\title{
UNIVERSALIDADE DOS DIREITOS HUMANOS E DIVERSIDADE CULTURAL: O Diálogo Intercultural Como Meio de Preservação da Identidade e Autonomia dos Povos Indígenas
}

http://dx.doi.org/10.21527/2176-6622.2019.52.21-36

Recebido em: 19/3/2019

Modificações requeridas em: 21/6/2019

Aceito em: 29/9/2019

Angela Jank Calixto

Doutoranda em Direito pela USP - Universidade de São Paulo. Mestre em Direito pela UFMS - Universidade Federal de Mato Grosso do Sul. Segunda vice-presidente da Federação Nacional dos Pós-Graduandos em Direito. Assistente editorial da Revista Direito UFMS. Analista Judiciário do TJMS. http://lattes.cnpq.br/4494411388014641. angelajcalixto@gmail.com

\section{Luciani Coimbra de Carvalho}

Doutora e mestre em Direito do Estado pela Pontifícia Universidade Católica de São Paulo - PUCSP. Professora-adjunta da Graduação e do Mestrado em Direito da Universidade Federal de Mato Grosso do Sul - UFMS, Mato Grosso do Sul (Brasil). http://lattes.cnpq.br/5525412512514279. lucianicoimbra@hotmail.com

\section{RESUMO}

A afirmação da universalidade dos direitos humanos depende necessariamente da observância da diversidade cultural existente. No âmbito local, destaca-se que o reconhecimento da identidade cultural dos povos indígenas constitui questão de essencial importância para se assegurar referida diversidade e para o estabelecimento de uma relação harmoniosa entre direitos humanos e o direito costumeiro indígena. Diante, no entanto, da tensão existente entre algumas práticas tradicionais indígenas e direitos humanos, constata-se a necessidade de adoção de uma postura dialógica pelos tribunais internacionais e estatais com as comunidades locais, para superar a resistência à aceitação da diversidade cultural indígena. Ante a relevância de se identificar o diálogo como meio para a construção de um universalismo consciente das diferenças, procura-se com este trabalho, por meio de uma pesquisa qualitativa e da adoção do método dedutivo, delimitar como o diálogo intercultural tem se firmado na América Latina por meio da atuação de Cortes Constitucionais e demonstrar os rumos para a coexistência do Direito Estatal e Internacional com o Direito local das comunidades indígenas. Conclui-se que, apesar dos avanços, a defesa da universalidade e transculturalidade dos direitos humanos ainda necessita passar por um longo processo, com as Cortes nacionais e internacionais de Justiça possuindo papel relevante na harmonização de interesses.

Palavras-chave: Direitos humanos. Diversidade cultural. Diálogo intercultural. Povos indígenas.

UNIVERSALITY OF HUMAN RIGHTS AND CULTURAL DIVERSITY:

INTERCULTURAL DIALOGUE AS A WAY TO PRESERVE THE IDENTITY AND AUTONOMY OF THE INDIGENOUS PEOPLES

\section{ABSTRACT}

The possibility of stating that human rights are universal necessarily depends on the observance of the existing cultural diversity. At the local level, it should be noted that in order to ensure such diversity and to establish a harmonious relationship between human rights and indigenous customary law, the recognition of the cultural identity of indigenous peoples is a matter of fundamental importance. However, due to the tension between some traditional indigenous practices and human rights law, it is necessary that international and state courts adopt a dialogical attitude with local communities, as a way to overcome the resistance to the acceptance of indigenous cultural diversity. In view of the importance of identifying dialogue as a means for the construction of a universalism characterized for being conscious of the differences, it is sought through this paper to delineate, by a qualitative research and the adoption of the deductive method, how intercultural dialogue has been established in Latin America through the performance of Constitutional Courts and to demonstrate the path for the coexistence of state and international law with the local law of indigenous communities. It is concluded that, despite advances, the defense of the universality and transculturality of human rights still needs to go through a long process, the national and international courts of justice having a relevant role in the harmonization of interests.

Keywords: Human rights. Cultural diversity. Intercultural dialogue. Indigenous peoples.

SUMÁRIO

1 Introdução. 20 Processo de Construção dos Direitos Humanos Como Direitos Universais e a Questão do Relativismo Cultural. 3 Diálogos Interculturais e o Processo de Construção de um Universalismo Consciente das Diferenças. 4 Povos Indígenas e Diversidade Cultural: O Papel das Cortes na Garantia da Coexistência e Respeito à Identidade Cultural na América Latina. 5 Conclusão. 6 Referências. 


\section{INTRODUÇÃO}

No debate contemporâneo acerca de direitos humanos, a questão da universalidade desses direitos e sua aplicabilidade irrestrita a todos os distintos povos e culturas que constituem a comunidade global possui especial relevância. Em que pese a afirmação de que o longo processo de luta pela proteção, no cenário internacional, de alguns direitos inerentes a toda e qualquer pessoa levou ao reconhecimento da universalidade dos direitos proclamados a partir da Declaração de Direitos Humanos de 1948, até hoje evidenciam-se controvérsias e discussões acerca da possibilidade de caracterizar tais direitos como universais, destacando-se, nesse sentido, as críticas apresentadas por Boaventura de Sousa Santos (2003).

A ausência de consideração das peculiaridades locais e culturais no processo de construção dos direitos humanos levou ao surgimento de movimentos de resistência à pretensão da comunidade internacional de impor a todos os países os valores morais estabelecidos na Declaração de 1948. Surgidos a partir da ideia de relativismo moral, o qual se contrapõe totalmente ao universalismo dos direitos humanos, esses movimentos têm se desenvolvido sob a influência da ideia da necessidade de estabelecimento de uma relação dialógica entre distintos povos, para que seja possível a formação de um universalismo de confluência que considera as peculiaridades locais no processo de construção de direitos.

Entre os movimentos emancipatórios, um de grande relevância, sobretudo na América Latina, diz respeito à luta pelo respeito do direito das comunidades indígenas a sua autonomia e à preservação de sua identidade cultural. Apesar de o direito à diversidade cultural ter tido pouco espaço nas normas internacionais de direitos humanos e de os povos indígenas terem a princípio sido excluídos do processo de construção de tais direitos, atualmente se reconhece o direito à diferença, admitindo-se a necessidade de respeito às tradições e ao direito costumeiro indígena como forma de garantia da coexistência entre os povos tradicionais e a cultura dominante de determinada sociedade.

A despeito de tal reconhecimento, contudo, as tensões entre o direito costumeiro indígena e os direitos humanos são uma constante, sobretudo em razão de os valores essenciais de cada ordem surgirem de experiências históricas muito diversas. Assim, exige-se o contínuo esforço dos tribunais internacionais e estatais em adotar uma postura dialógica com as comunidades tradicionais na análise de casos concretos submetidos a sua apreciação, para que ao mesmo tempo em que se procure garantir que não haja o total desrespeito às normas de direitos humanos reconhecidas no cenário internacional, busque-se garantir o respeito à diversidade e à coexistência.

Denota-se, entretanto, que em que pese a imprescindibilidade do estabelecimento de um diálogo, uma interação, entre os diversos níveis de proteção dos direitos humanos para a construção de um universalismo consciente das diferenças, ainda há grande resistência na promoção dessa articulação, diante da não aceitação da diversidade cultural e da consequente ingerência estatal no Direito local. Tal resistência cria óbices ao pleno desenvolvimento do direito à diversidade, impede a caracterização dos direitos humanos como universais e possui a capacidade de levar à aniquilação de culturas inteiras.

Assim, diante de tal problemática e da ausência de delimitação precisa dos contornos do diálogo entre culturas, torna-se necessário evidenciar a possibilidade de seu estabelecimento e demonstrar como essas interações têm ocorrido no âmbito da América Latina por meio das diferentes Cortes de Justiça, para que a partir do exemplo de algumas Cortes Constitucionais da região promovam a articulação necessária com as comunidades indígenas para a integral proteção dos direitos humanos, aqui incluído o direito à diversidade cultural. Nesse sentido, objetiva-se com este trabalho identificar como o diálogo tem se firmado na América Latina, demonstrando a plausibilidade de coexistência do Direito Estatal e Internacional com o direito local das comunidades indígenas, sem que essa coexistência afronte a proteção conferida pela comunidade internacional aos direitos humanos.

Para tanto, a partir de uma pesquisa qualitativa, de cunho bibliográfico e documental (GIL, 2002), e por meio da adoção do método dedutivo, em um primeiro momento será analisado o surgimento do embate entre o universalismo dos direitos humanos e a necessidade de relativização desses direitos, para, em um segundo momento, demonstrar como é possível, por meio do diálogo intercultural, a construção de um universalismo de confluência, o qual leva em consideração a diversidade cultural no processo de construção do Direito. Por fim, adentrar-se-á mais especificamente no tema, uma vez que será analisada a questão indígena, 
demonstrando como a relação dialógica tem sido estabelecida na América Latina a partir da atuação de Cortes Constitucionais, como forma de garantia da coexistência e do respeito à autonomia e identidade cultural indígena, sem que com isso haja o completo abandono da posição universalista dos direitos humanos.

\section{O PROCESSO DE CONSTRUÇÃO DOS DIREITOS HUMANOS COMO DIREITOS UNIVERSAIS E A QUESTÃO DO RELATIVISMO CULTURAL}

No estudo da proteção conferida aos direitos humanos no cenário global, observa-se que tais direitos são identificados por uma característica considerada de essencial importância, qual seja, sua universalidade, consistente, segundo Ramos (2014, p. 82), na possibilidade de sua atribuição "a todos os seres humanos, não importando nenhuma outra qualidade adicional, como nacionalidade, opção política, orientação sexual, credo, entre outras". Ante a importância que a integral tutela dos direitos humanos tem adquirido para a comunidade global, referidos direitos são assim caracterizados em razão de serem concebidos como inerentes ao homem, como valores anteriores e superiores a qualquer Estado ou forma de organização social, sua titularidade derivando da mera condição de pessoa (TRINDADE, 2007).

Aponta lovane (2007) que a referência à universalidade dos direitos humanos remonta ao início da formação de teorias do Direito Natural no século 17, ante a influência da filosofia iluminista, que assumia a noção de que todos os seres humanos são iguais e nascem com alguns direitos inalienáveis. ${ }^{1}$ Diante da igualdade abstrata afirmada no período, igualdade essa que constitui noção básica da doutrina liberal clássica dos direitos humanos, reconheceu-se pela primeira vez que os direitos são válidos em qualquer local, independentemente da cultura particular e do local de nascimento.

A dignidade da pessoa humana, para essa concepção, partindo de uma individualistic approach característica da tradição liberal, relacionava-se estritamente com a autonomia individual da pessoa, não dependendo de sua condição como membro de uma comunidade ou de um grupo social, de modo que bastava que a cada indivíduo fosse garantido o direito individual de perseguir seu próprio direito subjetivo, sem interferência do Estado e das instituições públicas, para que os direitos humanos fossem respeitados (IOVANE, 2007).

Em que pese, entretanto, a possibilidade de se identificar certa tendência à caracterização dos direitos humanos como direitos universais desde a Revolução Francesa, denota-se que a afirmação de sua universalidade possui vínculo indissociável com o processo de internacionalização de referidos direitos, iniciado com o surgimento do Direito Humanitário, da Liga das Nações e da Organização Internacional do Trabalho e consolidado na segunda metade do século 20, processo esse decorrente da formação de ramo próprio do Direito Internacional destinado à tutela de tais direitos (qual seja, o Direito Internacional dos Direitos Humanos - DIDH).

Consoante apontado por Cançado Trindade (2007), a partir desse processo evolutivo os direitos humanos passam a ser definidos como materialmente universais em razão de se vislumbrar que eles decorrem da consciência jurídica universal, a qual reconhece e dá expressão concreta aos direitos inerentes a todo ser humano. Passa-se a reconhecer, assim, que os direitos humanos fundamentam-se, em última instância, na ética coletiva e na conviç̧ão largamente estabelecida na comunidade internacional de que a dignidade humana exige o respeito a certos bens e valores em quaisquer circunstâncias (COMPARATO, 2010).

Da mesma forma, passam eles a ser reconhecidos como direitos formalmente universais, em razão de o DIDH formar um corpus juris consolidado e aceito no cenário internacional que, a partir da positivação de garantias e direitos dos indivíduos, estabelece como propósito comum da comunidade internacional a proteção do indivíduo em toda e qualquer circunstância (CANÇADO TRINDADE, 2007).

\footnotetext{
Dentre os filósofos iluministas que buscavam a fundamentação, justificação ou legitimação de normas e condutas vinculadas a princípios morais, destaca-se o pensamento de Immanuel Kant, cuja contribuição foi essencial para a noção de universalidade de alguns direitos humanos básicos. Em sua obra Fundamentação da metafísica dos costumes, o filósofo traz importante reflexão, ao voltar-se para o problema da moralidade humana e ao buscar relacioná-la ao Juízo Sintético a priori fundamental (o princípio supremo da moralidade ao qual toda ação deve submeter-se), qual seja, o imperativo categórico. O filósofo, na busca pela identificação de uma Filosofia Pura Moral, apoiada somente em sua parte formal e metafísica e extraída de si mesma de forma lógica e racional, tece considerações acerca da moralidade, concebendo a existência de leis universais morais que regem a ação humana de maneira necessária e universal, universalidade essa que é livre de condições empíricas históricas, sociais, psicológicas e antropológicas. Para o teórico, a razão fundamenta o imperativo categórico determinante da vontade humana e serve de lei universal, a qual pode variar seu conteúdo no espaço e no tempo, mas não no que se refere à atividade racional (KANT, 2007).
} 
Nesse tocante, salienta-se que o marco da universalidade e inerência dos direitos humanos e de seu reconhecimento como formalmente universais foi a edição da Declaração Universal de Direitos Humanos de 1948, primeiro tratado de alcance universal que reconheceu os direitos fundamentais dos seres humanos e impôs o dever de os Estados assegurarem a dignidade e o valor de todos, dispondo bastar a condição humana para a titularidade de direitos (RAMOS, 2014). O conceito de universalidade, a partir da Declaração, é assim reconhecido como princípio fundamental dos direitos do homem, sendo percebido não apenas como um ideal a ser perseguido, mas também como um princípio de interpretação e de instituição (CASSIN, 1951).

Iniciado o processo de internacionalização e consequente universalização dos direitos humanos a partir da Declaração de 1948, este se consolidou com a posterior expansão da produção normativa internacional em prol dos direitos humanos (declarações, convenções, pactos, tratados, etc.) e com a criação de mecanismos de fiscalização de possíveis violações e de responsabilização dos Estados e indivíduos que cometem tais violações (DIMOULIS, 2014). A intensa produção de documentos internacionais e regionais contribuiu, dessa forma, para o desenvolvimento da ideia de que os direitos humanos possuem caráter universal, uma vez que, com a formação de um complexo aparato de proteção jurídica global dos direitos humanos, "afirmou-se inequivocadamente a legitimidade da preocupação de toda a comunidade internacional com a promoção e a proteção dos direitos humanos em todo o mundo (obrigação erga omnes de proteção), - que impulsionou o processo de universalização dos direitos humanos" (CANÇADO TRINDADE, 2007, p. 217).

Frisa-se que a universalidade dos direitos humanos é reafirmada em uma série de documentos de essencial importância no que diz respeito à proteção de direitos humanos, como na Convenção Europeia de Direitos Humanos (1950), no Pacto Internacional de Direitos Civis e Políticos (1966) e na Convenção Americana de Direitos Humanos (1969), destacando-se sua reiteração, ainda, na Proclamação de Teerã, emitida na 1a Conferência Mundial de Direitos Humanos da ONU, em 1968, e na Declaração de Viena de 1993, na qual a concepção individualista da dignidade humana permeia todo o preâmbulo da Declaração e encontra-se evidenciada em seus artigos 1ㅇ e 5‥ Nesses documentos, a universalidade abstrata dos direitos humanos é ressaltada, apontando-se que basta a condição de pessoa para a aplicabilidade das normas internacionais de direitos humanos (IOVANE, 2007).

Desde a década de 60, entretanto, essa noção de universalidade passou a ser desafiada, ante a evolução da doutrina do relativismo cultural, a qual preconiza que os valores são confinados a certos tempos e lugares e a percepções, sociedades e culturas particulares, sendo eles, pois, estritamente dependentes do contexto social, cada cultura possuindo uma interpretação própria acerca dos direitos humanos (MAZZUOLI, 2015).

Nesse sentido, segundo os defensores dessa doutrina, apesar de a Declaração de Direitos Humanos de 1948 e os instrumentos internacionais posteriores declararem os direitos humanos como universais, tais instrumentos, na realidade, apenas se referem a tentativas de descrever como universais uma particular concepção de direitos humanos, baseada no liberalismo político, no individualismo e na maior importância concedida aos direitos civis e políticos em detrimento dos direitos econômicos, sociais e culturais (GOMEZ ISA, 2014).

A presença de apenas pressupostos ocidentais na criação e construção da concepção contemporânea de direitos humanos é muito bem esclarecida por Boaventura de Sousa Santos (2003), o qual salienta que o conjunto de valores defendidos a partir da Declaração de 1948 é muito facilmente distinguível de outras concepções de dignidade humana defendidas por outras culturas. Como pontua o autor, isso é verificável, sobretudo, diante do fato de tais valores deterem conotação essencialmente individual, em detrimento do coletivo, de serem concebidos como superiores aos valores defendidos em outras realidades e de a Declaração de 1948 ter sido elaborada sem a participação da maioria dos povos do mundo, deixando, como frisa Gomez Isa (2014), de considerar as realidades locais e os diferentes meios de proteção da dignidade da pessoa humana nessas localidades.

Nesta percepção, os direitos humanos, da forma como concebidos pela comunidade internacional, decorreriam não de um processo de globalização contra-hegemônica ou bottom up, mas sim de uma espécie de globalização hegemônica ou top down, imposto pela sociedade ocidental ao restante do globo, sem considerar, e até mesmo marginalizando, as particularidades de cada cultura (SANTOS, 2003). Diante de tal constatação, o autor salienta que em que pese o fato de na atualidade ser possível se evidenciar o progressivo surgimento de movimentos contra-hegemônicos destinados à elaboração de uma concepção de direitos humanos que de certa forma leve em consideração as minorias, ainda assim constata-se que em muitos aspectos os 
direitos humanos ditos "universais" não dizem respeito a uma cultura global, mas sim se referem a direitos impostos por uma parcela da comunidade global sobre as demais, que procura universalizar seus valores máximos em detrimento daqueles de outros povos, induzindo, nas palavras de Mazzuoli (2015), a progressiva destruição da diversidade.

Ante tal percepção, surgiram variadas críticas à concepção universal de direitos humanos. Como bem resume Érica de Souza Pessanha Peixoto (2007), defende-se a impossibilidade de um universalismo em razão de diversos fatores, como as constatações de que a noção de direitos inerentes ao homem contrapõe-se à noção de deveres proclamados por muitos povos; a visão universal é eminentemente antropocêntrica, o que não é compartilhado por outras culturas; o universalismo analisa um homem descontextualizado, ignorando que este se define por seus particularismos; a proteção dos direitos humanos acaba sendo utilizada de forma vinculada a interesses políticos e econômicos; não houve a adesão formal, por muitos Estados, a alguns tratados de direitos humanos.

Diante de tais constatações, a crítica relativista passa, então, a permear a discussão acerca da afirmação da universalidade dos direitos humanos, trazendo importante contribuição ao ressaltar a necessidade de cautela quanto à tendência de se afirmar uma ética universal de primazia de valores ocidentais, a qual, por vezes, mostra-se intolerante e desrespeitosa quanto às especificidades culturais (SANTOS, 2011). Surge a defesa da ideia, nessa percepção, de que os direitos humanos referem-se a direitos pertencentes não à cultura global, mas a uma cultura dominante específica, moralmente individualista e distante do contexto social e cultural, a qual busca universalizar sua visão de mundo em detrimento das sociedades que caracteristicamente relacionam a moral com cultura.

Do mesmo modo, entretanto, que os relativistas criticam os universalistas, estes também apresentam críticas ao relativismo cultural, salientando que tal primazia ao coletivo possibilitaria graves violações aos direitos dos indivíduos, a posição relativista revelando "o esforço de justificar graves casos de violações dos direitos humanos que, com base no sofisticado argumento do relativismo cultural, ficariam imunes ao controle da comunidade internacional" (PIOVESAN, 2013, p. 213).

É nesse contexto de embate entre a posição relativista e a posição universalista que surge a defesa do estabelecimento de um processo que não anula nenhuma das doutrinas e que ao mesmo tempo não aceita apenas uma ou outra em sua totalidade. Trata-se da defesa de ideias que tendem a afirmar a possibilidade de um universalismo de confluência, o qual, segundo Flávia Piovesan (2009), ao respeitar a diversidade cultural e afirmar a imprescindibilidade de participação das distintas culturas no processo de construção do Direito, possui o condão de assegurar a legitimidade do processo de criação de parâmetros internacionais mínimos voltados à proteção dos direitos da humanidade.

Denominada de distintos modos (universalismo de confluência, multiculturalismo, interculturalismo, transconstitucionalismo, diálogo intercultural, etc.), essa ideia, que será tratada no próximo tópico, considera que a universalidade apenas poderá ser construída por meio de uma relação dialógica, devendo ser tratada como um objetivo comum da humanidade e não como ponto de partida na determinação do fundamento dos direitos humanos.

\section{DIÁLOGOS INTERCULTURAIS E O PROCESSO DE CONSTRUÇÃO DE UM UNIVERSALISMO CONSCIENTE DAS DIFERENÇAS}

As condições para o surgimento dos direitos humanos na sociedade contemporânea invariavelmente relacionam-se a um dissenso estrutural, diante da pluralidade social e cultural e da consequente heterogeneidade de interesses e valores defendidos em cada sociedade. Diante disso, como argumenta Neves (2009), o estudo dos direitos humanos e da interpretação a eles conferida em cada sociedade é altamente complexo, as controvérsias surgindo justamente ante a possibilidade de uma pluralidade conflituosa de interpretações desses direitos, bem como diante do fato de algumas ordens normativas serem inclusive avessas à ideia de direitos humanos como direitos universais, como visto. 


\section{Debate}

Ante a fragmentariedade cultural e a percepção de que uma cultura isolada não pode pretender impor-se sobre outras sociedades, surge o embate, no campo dos direitos humanos, acerca da possibilidade de se afirmar que estes são universais e, em sentido contrário, a imprescindibilidade de rejeição dessa universalidade, perante a magnitude das distinções culturais e a impossibilidade de se afirmar a existência de uma moral universal.

Ante a globalização da economia e da sociedade e a interdependência dela decorrente, contudo, defende-se que nem uma e nem outra tese possa ser concebida como resposta, visto que a mera imposição de determinados valores sobre uma sociedade não garante a legitimidade da proteção conferida pelos direitos humanos, do mesmo modo que a negação da existência dos direitos humanos e da interdependência entre distintas ordens possibilita o cometimento de atrocidades que não são aceitas pela comunidade internacional no geral.

Nesse cenário de fragmentariedade e interdependência, vislumbra-se que apenas por meio do reconhecimento do pluralismo e da necessidade de articulação de distintas concepções e culturas é possível que se concretize o objetivo visado pela comunidade internacional de se garantir a proteção dos indivíduos em âmbito local, nacional, regional, supranacional ou internacional (ACOSTA ALVARADO, 2015), ao mesmo tempo que se protege o direito à cultura, possibilitando a construção de um universalismo consciente das divergências culturais existentes (PIOVESAN, 2009).

Destaca-se, nesse sentido, o pensamento de Habermas (2003), o qual salienta que a adoção de uma postura universalista que se mostra preocupada em evitar falsas abstrações precisa, necessariamente, aproveitar discernimentos proporcionados pela teoria da comunicação.

O autor, em sua Teoria do Agir Comunicativo, explicita que o agir corresponde a um processo circular, em que o ator da comunicação é ao mesmo tempo iniciador de uma ação e produto das tradições nas quais se encontra, dos grupos solidários aos quais pertence e dos processos de socialização nos quais se cria (HABERMAS, 2012). Nesse sentido, partindo da constatação de que as interpretações de mundo variam de acordo com a realidade social e natural (com o mundo objetivo e social) em que determinado ator se encontra, o autor destaca ser necessário, para o estabelecimento de um processo de comunicação destinado à consolidação de entendimentos comuns, o afastamento de nossa visão egocêntrica do mundo e a consideração dos outros sujeitos existentes no processo de interpretação da realidade. ${ }^{2}$

Assim, consoante os ensinamentos de Habermas (2003), a mera afirmação da universalidade não pode ser validada à custa da constatação de que as sociedades e as concepções de direitos humanos são diferentes entre si, de modo que por mais que se exija a deferência moral de todos (indivíduos e Estados) que convivem em comunidade para seu próprio funcionamento, também se demanda a aceitação das potenciais diversidades existentes. Por conseguinte, "uma lei é válida no sentido moral quando pode ser aceita por todos, a partir da perspectiva de cada um" (HABERMAS, 2003, p. 44), posto que, uma teoria dos direitos, se entendida de forma adequada, jamais fecha os olhos para as diferenças culturais existentes.

Da mesma forma, importante é a contribuição de Amos Nascimento (2015), o qual, após discorrer acerca das ideias de John Rawls, Martha Nussbaum e Charles Taylor quanto à questão da universalidade dos direitos humanos, conclui que não obstante a pluralidade de perspectivas de mundo existentes é possível se chegar a tal ideia de universalidade, por meio de um processo por ele designado de overlapping consensus de diferentes perspectivas.

Nesse tocante, insta frisar que a ideia da necessidade de overlapping consensus encontra estrita relação com a noção de que os sistemas democráticos, como aponta Rawls (1987), são essencialmente caracterizados pela promoção de liberdades individuais básicas e, portanto, pelo pluralismo resultante da possibilidade da

\footnotetext{
Habermas (2012) constrói um conceito de racionalidade que encontra seus fundamentos nos processos de comunicação intersubjetiva. Segundo sua visão, a ação comunicativa surge a partir da interação de no mínimo dois sujeitos que estabelecem relações interpessoais com o objetivo de alcançar uma compreensão sobre determinada situação, com o fim de coordenar suas ações por meio do entendimento comum. Nessa interação, ante a existência de uma correlação direta entre ação comunicativa e o mundo da vida, em qualquer processo de comunicação há a reprodução das estruturas simbólicas do mundo da vida (cultura, sociedade e pessoa), exigindo-se que os atores da comunicação procurem harmonizar internamente seus objetivos para consolidar um sistema entrelaçado, em que diferentes perspectivas de mundo são consideradas.
} 
existência de doutrinas religiosas, filosóficas e morais diversas e até mesmo incompatíveis em um mesmo espaço. Assim, diante dessa pluralidade, a busca de um consenso por sobreposição de distintas concepções particulares torna-se uma exigência própria da Justiça e da unidade social.

Por meio da sobreposição das particularidades, com a inclusão de doutrinas e concepções conflitantes, possibilita-se adesão dos indivíduos a uma concepção geral sem que estes precisem abrir mão de suas concepções particulares, garantindo-se a coesão e estabilidade social necessárias em um contexto democrático (RAWLS, 1987). Baseando-se, pois, nesta perspectiva, Amos Nascimento (2015) defende que a ideia de universalidade apenas pode ser concebida como a soma consensual das diferentes perspectivas de mundo, dado que cada uma delas apenas retrata um fragmento da universalidade dos direitos, nenhuma delas sendo individualmente completa.

Isso posto, defende-se que os direitos humanos apenas podem ser considerados plenamente válidos quando passíveis de serem aceitos por todos, o que somente se torna possível com o respeito às diferenças e a articulação entre as distintas culturas na construção do Direito. Com o intercâmbio de culturas, ascendeu-se a um maior grau de percepção dos outros, das outras soluções, das outras moralidades, das outras legislações, percepção esta que nos leva a reavaliar nossas próprias crenças, a buscar ouvir o que o outro tem a nos ensinar. O motor expansivo dos direitos humanos e o que efetivamente fundamenta tais direitos advêm, pois, dessa percepção, consistente, na interpretação de Segato (2006), na ética da insatisfação que nos humaniza constantemente.

Como salienta Boaventura de Sousa Santos (2003), apenas por meio da consciência da incompletude de cada cultura é que é possível o diálogo necessário para a construção de uma política progressista de direitos humanos, a qual não desconsidera a legitimidade do Direito local. Torna-se necessário o reconhecimento, então, de que os valores defendidos por uma determinada cultura, por mais fortes que sejam, são tão incompletos quanto a cultura em si mesma, incompletude esta que somente é evidenciada, entretanto, a partir do intercâmbio e diálogo com o outro. O intercâmbio, dessa forma, possibilitaria a ampliação ao máximo da consciência da própria incompletude, constituindo pressuposto, assim, para o cosmopolitismo necessário para a construção dos direitos humanos.

Desta percepção, não é possível se falar em direitos humanos sem que haja um acolhimento das ideias formadas por distintos indivíduos, sociedades, culturas ou Estados e a aceitação da possibilidade de que os valores defendidos por diferentes povos sejam distintos, nenhum sendo superior ao outro, como forma de garantia da convivência. Exige-se, nessa perspectiva, o respeito à integralidade do outro, sua manifestação, a seu modo de ser e agir, a sua expressão cultural e religiosa (RECH, 2009). Reconhece-se o direito do outro de poder ser diferente, o que "implica numa educação para o escutar da voz diferente que brota de uma cultura também diferente que quer consolidar um diálogo na esfera da vida para que este seja verdadeiramente dialogal" (SIDEKUM, 2002, p. 78).

Assim, apenas por meio da interação e diálogo entre distintas culturas é que se torna possível o êxito no oferecimento de uma legítima proteção jurídica no cenário internacional. Isso porque, como aponta Gomez Isa (2014), para que o discurso de direitos humanos possa ser relevante em âmbito local, é necessário que ele esteja aberto à pluralidade existente e, em consequência, às diferentes culturas e valores de cada sociedade, de forma a tornar a proteção o mais localmente relevante possível.

Nessa concepção, recusa-se a universalidade apriorística da lógica da exclusão em nome dos direitos inatos do homem (CANDAU, 2000), ao mesmo tempo que se recusa o relativismo cultural, o qual, segundo Krohling (2008), esquece que as culturas não são hermeticamente fechadas em si mesmas, mas sim que em distintos níveis interagem e comunicam-se com as demais. Pressupõe-se o contato, para que as diferentes culturas não permaneçam estanques, como postula o relativismo cultural, e para que as diferenças, como salienta Ana Keila Mosca Pinez (2010), não contrariem os valores de direitos humanos como forma de justificar a segregação.

Ante a interconexão direitos humanos e cultura, tem-se, como bem salientado por Sparemberger e Rangel (2013, p. 272), que "o momento é de reflexão, para poder visualizar-se um caminho que seja dialógico entre as mais diversas culturas, sem que se neguem mutuamente, o que implica a aceitação da diversidade e a compreensão da humanidade do ser", sob pena de a não aceitação levar a maiores conflitos e, ainda, ao extermínio de culturas inteiras. Segundo essa perspectiva, que, consoante Taylor (1998), constitui-se como 
condição para a própria sobrevivência das sociedades multiculturais, deve-se reconhecer que no processo de construção do Direito participa uma infinidade de culturas, todas detendo igual valor (GALINDO, 2004), a reciprocidade, a interface e a articulação coletiva revelando-se de essencial importância para a harmoniosa interação (KROHLING, 2008).

Assim, com a abertura à pluralidade e à diversidade e com o reconhecimento de que os direitos não são abstratos, mas sim necessariamente relativos e influenciados pelo contexto social (GOMEZ ISA, 2014), possibilita-se a elaboração de uma concepção mista de direitos humanos, a qual, ao invés de recorrer a falsos universalismos, organiza-se em uma amplitude de sentidos locais (SANTOS, 2003).

Frisa-se que tal articulação mostra-se necessária na atualidade, uma vez que os compromissos axiológicos assumidos pelos Estados na proteção do indivíduo e, concomitantemente, na proteção de seu direito à cultura, reclamam empenhos para que a tutela ocorra de forma legítima, com a participação de todos e sem a imposição da cultura dominante sobre as demais. Consiste, por outro lado, no desafio de respeitar as diferenças existentes e ao mesmo tempo de integrar os diferentes sistemas em uma unidade que não anule tais diferenças, mas que "ative o potencial criativo e vital da conexão entre diferentes agentes e entre seus respectivos contextos" (FLEURI, 2003, p. 497).

Diante de tais premissas, vislumbra-se a necessidade de uma abertura dos Estados ao pluralismo cultural, como forma de assegurar o respeito às culturas de todos os povos, sejam estes de outros Estados, seja dentro do próprio território nacional (indígenas, por exemplo). A relação entre os distintos ordenamentos, nessa perspectiva, deve se construir de forma conjunta, compartilhada e harmonizada, o que apenas ocorre por meio do reconhecimento mútuo da validade e legitimidade de todos os sistemas sociais, de todos os ordenamentos e de todas as culturas, sem reconhecer a superioridade de um sobre o outro (QUEIROZ, 2009).

É preciso notar, como destaca Amartya Sen (2000), que há mais inter-relações e mais influências culturais mútuas no mundo do que aqueles que se alarmam com a perspectiva da subversão cultural normalmente constatam. Não obstante se vislumbre frequentemente a fragilidade de determinadas sociedades com culturas diferenciadas, não se deve subestimar nosso poder de aprender coisas com diferentes culturas sem sermos assoberbados pela experiência e sem impormos nossa própria concepção cultural a outras nações.

Nesse tocante, denota-se que a partir da aceitação da ideia de interdependência e necessidade de articulação, permite-se espaço para que as ordens locais, como é o caso das ordens indígenas, desenvolvam-se dentro de um Estado, mesmo que haja algumas divergências entre o que os povos tradicionais consideram de suma importância e o que o Estado defende e impõe como valores fundamentais da sociedade. Isso porque se rejeita a consideração de que o direito existente nas comunidades tradicionais refere-se a um direito primitivo e inferior, aceita-se que as condutas e ações desses povos devem ser levadas em consideração e se admite que o Estado e a comunidade internacional não possuem o monopólio das normas ou o monopólio da interpretação acerca dos direitos humanos.

Dessa forma, a abordagem intercultural, tal como apresentada, possibilita a sobrevivência das sociedades multiculturais, a partir do entendimento e consequente respeito a suas identidades culturais, criando condições para a formação de uma concepção de direitos humanos consciente das diferenças existentes.

\section{POVOS INDÍGENAS E DIVERSIDADE CULTURAL: \\ O Papel das Cortes na Garantia da Coexistência e Respeito \\ à Identidade Cultural na América Latina}

Sob a bandeira do interculturalismo e da necessidade de estabelecimento de uma relação dialógica para o estabelecimento de um universalismo de confluência surgem diversos movimentos emancipatórios em defesa da preservação da diversidade cultural como forma de assegurar a integral proteção dos direitos humanos. Entre tais movimentos, caracterizados pela luta contra a supressão das identidades culturais pela globalização, um de essencial importância refere-se ao movimento de preservação das tradições e das culturas indígenas, movimento esse que exige a constante interação entre culturas para o respeito à autonomia e identidade indígenas e para que não haja a imposição da cultura nacional sobre a local. 
Como referido, a realização da Justiça por meio do DIDH pressupõe que seja considerada a diversidade cultural existente, aqui incluídos os povos tradicionais. Nessa acepção, a criação de circunstâncias adequadas para o pleno desenvolvimento da cultura indígena, de forma a garantir a coexistência entre os povos tradicionais e a cultura dominante de determinada sociedade, constitui importante parâmetro para a realização da Justiça internacional.

No âmbito da América Latina, a questão da preservação da identidade cultural dos povos indígenas destaca-se como sendo de suma importância, seja em razão da quantidade de comunidades indígenas existentes na região, seja em razão do histórico de negligência da diversidade desses povos pelos Estados e pela ordem internacional no geral. A busca pela convergência a partir de um processo de interação, articulação entre a ordem estatal e a ordem indígena local e o respeito à diferença de valores defendidos por tais povos, constitui tarefa essencial, exigindo dos tribunais nacionais a adoção de uma postura dialógica e alteritária para que se assegurem aos povos indígenas os direitos humanos em sua integralidade, aqui incluído o direito à diversidade cultural.

Antes de buscar evidenciar de que forma a relação dialógica tem ocorrido na região, entretanto, é importante que se esclareça a evolução da proteção conferida à diversidade cultural do indígena no âmbito da proteção conferida pelo DIDH e pelos Estados da América Latina, como forma de evidenciar em que sentido essa proteção, hoje, deve ser assegurada pelos Estados na condução de suas políticas públicas e como forma de se vislumbrar a possibilidade e necessidade de estabelecimento de uma relação dialógica na região.

Nesse tocante, consoante mencionado por lovane (2007), frisa-se que apesar de a princípio os direitos humanos serem concebidos como universais e independentes, havendo pouco espaço para diversidade, essa diversidade, hoje, é correntemente apresentada em uma série de resoluções internacionais. Há, assim, um reconhecimento internacional do igual valor de todas as culturas.

Com relação aos instrumentos mais importantes ao fortalecimento dos direitos dos povos indígenas no Direito Internacional, para além da proteção oferecida pelas normas internacionais de alcance geral e de proteção de minorias, lista-se a Convenção 107 da OIT, de 1957, destinada a garantir a proteção e integração da comunidade indígena e outras populações tribais ou semitribais em países independentes; a Convenção 169 da OIT, de 1989, relativa aos direitos de indígenas e tribos nos países independentes que substituiu a primeira; a Convenção sobre a Proteção e Promoção da Diversidade das Expressões Culturais (2005), a qual, na visão de Kugelmann (2007), se constitui como a expressão mais proeminente da promoção da diversidade cultural em plano internacional, a partir do reconhecimento da diversidade cultural entre Estados e dentro destes como uma característica essencial da humanidade; e, por fim, a Declaração de Direitos dos Povos Indígenas, elaborada em 1993 e adotada pelo Conselho de Direitos Humanos em 2006, concebida como um passo necessário do Direito Internacional para a afirmação do direito dos indígenas de deterem uma identidade específica e para assegurar sua sobrevivência (GILBERT, 2007).

Tais documentos consagram o direito dos indivíduos e dos grupos culturalmente divergentes, incluídos os povos indígenas, ao exercício positivo de suas diferenças, questionando a universalidade dos direitos humanos ante a necessidade de respeito à diversidade cultural como forma de proteção à dignidade humana (GODINHO, 2010).

Apesar de não vinculante, a Declaração de Direitos dos Povos Indígenas utiliza-se de direitos previstos nos documentos anteriores para resumir os standards mínimos que são necessários para garantir à comunidade indígena sua integridade cultural e sua autonomia. As principais inovações foram o reconhecimento da personalidade jurídica dos povos indígenas, do direito à exigência tanto de direitos individuais como coletivos e do direito à autodeterminação, bem como a afirmação da igualdade dos indígenas a outros povos (GODINHO, 2008).

Desde o preâmbulo da Declaração evidencia-se uma mudança de perspectiva da comunidade internacional, a qual, após séculos de opressão e assimilação cultural, passa a afirmar a imprescindibilidade do estabelecimento de um diálogo dos Estados e da comunidade internacional com os povos indígenas, como forma de respeito a sua integridade e autonomia (GILBERT, 2007) e como forma de estabelecimento de uma relação mais harmoniosa e cooperativa entre Estados e os indígenas que ocupam parte do território estatal (GODI- 
NHO, 2008). Reconhece-se, assim, que o direito indígena local e os direitos humanos proclamados em âmbito global coexistem e tangenciam-se no processo de busca pela construção de valores que possuem a capacidade de se caracterizarem como interculturais (GOMEZ ISA, 2014).

Ao estabelecer um balanço entre direitos individuais e coletivos, a Declaração ilustra que o reconhecimento de direitos coletivos não necessariamente leva à negação de direitos individuais (GILBERT, 2007). Tal fato configura um avanço na afirmação da existência de uma progressiva construção de direitos humanos que levam em consideração as particularidades locais e culturais, abrindo-se caminhos para a progressiva interação intercultural.

Da mesma forma que no cenário internacional, vislumbra-se que no âmbito do Direito doméstico dos Estados latino-americanos houve grandes alterações nas Constituições nacionais, para a inclusão de demandas indígenas. Apesar de os dispositivos constitucionais ainda adotarem uma posição universalista, denota-se que as modificações constitucionais abriram caminho para debates acerca da possibilidade de existência, dentro de um mesmo território, de um pluralismo jurídico, ou seja, de um cenário em que diferentes pessoas com variados sistemas legais e distintas concepções de justiça coexistem (GOMEZ ISA, 2014).

Apesar, contudo, da proteção legal tanto no cenário internacional quanto no âmbito nacional, observa-se que, na prática, o estabelecimento de uma relação dialógica, baseada na alteridade, no respeito, na impossibilidade de imposição de uma forma cultural sobre a outra, não é tarefa fácil. Como argumenta Godinho (2010), a tensão existente entre o Direito dos povos indígenas e o Direito Estatal e Internacional é bastante evidente, havendo inúmeras divergências entre os direitos coletivos e o direito costumeiro desses povos e direitos humanos, como ocorre em casos, por exemplo, em que as tradições indígenas preveem condutas de discriminação contra a mulher ou sanções de grave violação à integridade física dos infratores, hipóteses em que os Estados e a comunidade internacional detêm grandes dificuldades em aceitar a perpetuação dessas práticas pelas comunidades indígenas.

É em decorrência dessas tensões que se apresenta a necessidade de estabelecimento de uma constante relação dialógica entre o Direito indígena e a proteção de direitos humanos, como forma de se buscar uma harmonização entre o interesse de preservação da integridade cultural do grupo com os direitos humanos internacionais. Nessa relação, deve-se objetivar aferir, no caso concreto, o significado de determinada prática para a preservação da cultura do grupo, por meio da constatação da existência ou não de dissenso interno contra a prática, constatação essa que possibilitaria identificar se a prática é ou não fundamental para a identidade cultural do grupo (GODINHO, 2010).

Nesse tocante, o papel das Cortes Constitucionais é crucial na defesa da autonomia do Direito local contra a interferência das autoridades centrais, ${ }^{3}$ cabendo a elas o papel central de, na análise do caso concreto, verificar se as limitações à diversidade cultural são legítimas, sendo justificadas para a preservação do indivíduo contra abusos justificados por práticas culturais radicais, ou se não o são, ante a constatação de que a limitação implica ofensa à integridade coletiva da comunidade (IOVANE, 2007).

No contexto da América Latina, essa tendência dialógica faz-se notar na jurisprudência da Corte Interamericana de Direitos Humanos (Corte IDH) e na jurisprudência de algumas Cortes Constitucionais dos países da região. Conforme referido por lovane (2007), ante uma extensiva interpretação realizada por juízes e tribunais estatais e regionais, identifica-se uma série de julgamentos que vão além da tradicional individualistic approach adotada pelos tribunais no geral, para satisfazer o objetivo coletivo da diversidade cultural. Apesar de em pequena escala e de não ser realizado por todos os Estados, evidencia-se o desenvolvimento de um diálogo na região, a exemplo de algumas Cortes Constitucionais e da Corte IDH servir de base para as demais na busca pela coexistência do local com o estatal e o internacional.

\footnotetext{
Cumpre frisar que não se ignora o papel de outras instituições e agentes na condução de diálogos interculturais, na procura pela harmonização do direito estatal com o direito costumeiro das comunidades indígenas, como é o exemplo da atuação de grupos missionários no caso dos indígenas Suruwahá no Brasil. Neste caso, emblemático no Brasil, a tribo considerava uma maldição e uma ameaça ao bem-estar da tribo o nascimento de crianças com anomalias físicas, ilegítimas ou gêmeas, tendo por costume o infanticídio de tais crianças. Evidencia-se, contudo, que ante o diálogo estabelecido, houve mudanças na visão do mundo de tal tribo, a qual passou a repensar tal atitude (PINEZ, 2010). Salienta-se, contudo, que considerando os fins deste trabalho, no qual se visa a identificar a relação dialógica promovida pelas Cortes Constitucionais e Internacionais de Justiça no tocante à matéria, não se entrará no mérito de casos em que não houve a atuação de tais Cortes no processo de formação de um universalismo consciente das divergências.
} 
Com relação à Corte IDH, salienta-se que esta, apesar de não julgar possível a invocação de manifestações culturais como forma de atentar contra valores reconhecidos universalmente como de observância obrigatória para o respeito a direitos fundamentais da pessoa humana, sendo contrária à doutrina do relativismo cultural, ressalta a importância de se conferir atenção especial à diversidade cultural, para que os direitos humanos sejam localmente relevantes e para que não haja a subsunção completa de um povo à cultura dominante (GOMEZ ISA, 2014).

Como exemplo disso destaca-se o caso Awas Tingni x Nicarágua (2001), considerado um marco decisivo no reconhecimento de direitos às comunidades tradicionais, posto que, a partir da "indigenização" de normas gerais de direitos humanos, garantiu o direito coletivo dos indígenas à propriedade de terras, em que pese apenas haver a previsão do direito individual à propriedade no Direito Internacional.

A Corte IDH, no caso, efetuou uma "interpretação evolutiva dos instrumentos internacionais de proteção dos direitos humanos" para considerar que a proteção do direito à propriedade "compreende, entre outros, os direitos dos membros das comunidades indígenas no contexto da propriedade comunal", ressaltando que, no caso dos indígenas há de se ter presente que "existe uma tradição comunitária sobre uma forma comunal da propriedade coletiva da terra, no sentido de que o pertencimento desta não se centra em um indivíduo, mas no grupo e sua comunidade", devendo ser reconhecido que a terra se constitui como "base fundamental para suas culturas, sua vida espiritual, sua integridade e sua sobrevivência econômica" (parágrafos 148 e 149). Nessa decisão, a qual foi reafirmada em diversas outras decisões da Corte IDH, ${ }^{4}$ a Corte IDH ressalta a possibilidade de adaptação dos direitos humanos em geral às especificidades dos grupos indígenas.

Do mesmo modo, temos o caso Aloeboetoe y Otros vs. Suriname (1991), em que a Corte IDH, na adoção de uma posição dialógica, recorreu ao direito costumeiro do grupo para reconhecer como legítima a prática da poligamia (a qual é proibida no Suriname), de modo a permitir a habilitação de um maior número de pessoas quando do pleito à indenização pela morte de alguns membros da comunidade.

Essas decisões, por reconhecerem a existência de direitos coletivos que devem ser assegurados às comunidades, como fator determinante para que não haja uma aniquilação cultural dos povos indígenas em razão da imposição da cultura dominante de um Estado sobre esses povos, têm servido de base para o desenvolvimento, na América Latina, de uma abordagem específica aos direitos humanos quando se trata de direitos dos povos indígenas (GILBERT, 2007), contribuindo para a progressiva construção de uma relação dialógica em que se asseguram os direitos da comunidade à preservação de sua identidade cultural.

Já no tocante às Cortes Constitucionais Latino-Americanas, insta observar que apesar de se vislumbrar a propensão para o estabelecimento de uma relação dialógica entre o local e o estatal e de se afirmar a imprescindibilidade de preservação da identidade cultural indígena pelos Estados, ainda há poucos julgados das Cortes Constitucionais de tais Estados em que efetivamente se evidencia a tentativa de se estabelecer uma relação dialógica entre o Direito Estatal e o Direito Local.

Denota-se que, no que diz respeito à preservação de direitos dos povos indígenas, as questões tratadas pelos Tribunais nacionais concentram-se basicamente no direito dos povos tradicionais à propriedade coletiva de suas terras e no reconhecimento da impossibilidade de exercício de atividades outras em tais terras que possam causar algum prejuízo à cultura e tradição indígenas. Há pouco enfrentamento de questões em que se vislumbram patentes tensões entre o DIDH e o Direito costumeiro local.

\footnotetext{
${ }^{4}$ A mesma abordagem foi aplicada, ainda, no caso Comunidad Indígena Yakye Axa vs. Paraguay (2005); no caso Povo Saramaka vs. Suriname (2007); no caso Comunidade Indígena Xákmok Kásek vs. Paraguai (2010); no caso Kichwa de Sarayaku vs. Equador (2012); no caso Povos Indígenas Kuna de Madungandí e Emberá de Bayano e seus Membros vs. Panamá (2014); e no caso Povo Indígena Xurucu e seus Membros vs. Brasil (2017).
} 


\section{Debate}

Após uma análise da jurisprudência de algumas Cortes Constitucionais da região, ${ }^{5}$ constatou-se que, para além da garantia do direito à propriedade coletiva, quase nenhuma Corte enfrentou casos relativos aos direitos dos povos indígenas e o contraste entre o Direito costumeiro e o Direito Estatal. Apenas a Corte Constitucional (CC) Colombiana e o Tribunal Constitucional Plurinacional (TCP) da Bolívia têm se mostrado pioneiros no processo de abertura da interpretação e prática de direitos humanos quando deparados com casos em que a visão de mundo de povos indígenas contrasta com direitos humanos, cabendo destacar alguns de seus julgados para que estes sirvam de parâmetro para as demais Cortes da região na busca pela coexistência entre o Direito indígena e o Direito Estatal e Internacional.

No tocante à CC Colombiana, denota-se que apesar de tal Corte ser cautelosa, uma vez que considera haver alguns direitos que não são passíveis de relativização em prol das diferenças culturais (a Corte lista como direitos que não são passíveis de relativização o direito à vida, a proibição da escravidão e a proibição da tortura), ela adota uma exemplar política de maximização da autonomia indígena e minimização das restrições, promovendo um diálogo entre o estatal e o local na busca pela coexistência de culturas em um mesmo território. Como afirma Gomez Isa (2014, p. 739), "os critérios aplicados pela Corte Constitucional constituem um progressivo e extremamente interessante mapa que busca prover diretrizes para a interpretação de direitos humanos universais a partir de uma perspectiva intercultural". ${ }^{6}$

Como exemplos da conduta da CC Colombiana e de seus esforços em aceitar as diferentes visões de mundo e a possibilidade de as comunidades atuarem de forma diversa ao preconizado pela Constituição Colombiana e pelas normas internacionais de direitos humanos, cita-se o caso da comunidade Embera-Chami, em que a CC relativizou a proibição ao estabelecimento de trabalho forçado, legitimando este como forma de punição em substituição ao aprisionamento. ${ }^{7}$ Após um estudo das circunstâncias do caso, a Corte pôde evidenciar que essa forma de punição decorria da perspectiva da comunidade de que a punição é aplicada como forma de dissuadir outros da prática de crimes e não como retribuição à prática de algum delito. Levou-se em consideração, pois, as percepções da comunidade, sem lhe impor determinada forma de conduta, em respeito aos diferentes valores defendidos por aquela comunidade.

Do mesmo modo, outro caso de grande repercussão diz respeito à comunidade $l k a$, a qual impôs aos membros da comunidade uma proibição à prática coletiva e pública de uma religião evangélica dentro da reserva indígena, em total afronta, pois, ao direito à liberdade religiosa tutelado na esfera internacional. No caso, após analisar os reflexos que a liberdade religiosa traria para a cultura local e evidenciar que para aquela comunidade não havia como dissociar a vida comunitária de sua religiosidade, a religião constituindo fator de união do grupo (de modo que o exercício público de outra religião afetaria toda a comunidade), concluiu que efetivamente a proibição era justificada, uma vez que colocava em risco o direito fundamental da comunidade à diversidade cultural e a sua integridade.

Em tais casos é possível evidenciar a disposição da Corte Colombiana no estabelecimento de um diálogo e na busca pela garantia do direito das comunidades indígenas a sua integridade cultural e a sua autonomia, em que pese à primeira vista que a ação da comunidade em cada caso pareça constituir uma violação aos direitos humanos (GOMEZ ISA, 2014).

No mesmo sentido, o TCP enfrenta diretamente a questão indígena, de modo a assegurar o direito de autorrepresentação dos indígenas e a equiparação constitucional da justiça comunitária indígena com o Judiciário nacional, como estipulado na Constituição Boliviana. Exemplo de atuação no que diz respeito ao re-

\footnotetext{
Foi realizada uma pesquisa da jurisprudência produzida pelas Cortes Constitucionais Superiores da Bolívia, Peru, Venezuela, Colômbia, Chile e Brasil, países esses marcados pela forte presença de indígenas em seu território, tendo sido evidenciado que, apesar da existência de diversos casos julgados relativos ao direito de propriedade indígena, houve pouco enfrentamento de outras matérias referentes à tensão entre direitos humanos e as tradições culturais das comunidades indígenas. Destaca-se que entre as Cortes mencionadas, apenas se evidenciou a tentativa da Corte Constitucional Colombiana em estabelecer uma relação dialógica com as comunidades indígenas, tendo esta se pronunciado em diversos casos acerca da necessidade de respeito à diversidade cultural e da possibilidade de os direitos humanos serem aplicados de forma diversa para tais comunidades, em observância à cultura e à tradição indígenas.

6 No original: "The criteria applied by the Constitutional Court constitute a progressive and extremely interesting road map that seeks to provide guidelines for interpreting universal human rights from an intercultural perspective".

Corte Constitucional de Colombia (C.C.) (Colombian Constitutional Court), Sentencia T-349/96, 8 Aug. 1996.
} 
conhecimento dos direitos e da diversidade indígena, posto que abraça os valores da interculturalidade e da plurinacionalidade como premissas de interpretação constitucional, o TCP corresponde ao Tribunal com mais conflitos envolvendo direitos indígenas.

Evidencia-se a existência de diversos julgados nos quais se reconhece aos povos indígenas sua qualidade de sujeitos coletivos e seu direito de conservar seus costumes, instituições, tradições, práticas e sistemas jurídicos, e se reconhece a igualdade jurídica das culturas e o dever de estabelecimento de diálogos interculturais entre os distintos sistemas jurídicos existentes no território boliviano. Destaca-se, nesse sentido, o diálogo promovido pelo TCP nas sentenças de número 1419/2012, 0698/2013, 1617/2013, 0363/2014 e 1016/2015S3, além de em outros julgados, nos quais se estabelecem as diretrizes de ação do Estado na condução de questões relacionadas a direitos indígenas e se fixa a necessidade de reconhecimento da autonomia e da identidade indígena.

Ainda, caso de essencial importância para elucidar a conferência de primazia ao direito e tradições indígenas pelo TCP refere-se ao caso 0295/2003, no qual o TCP, após analisar os costumes indígenas e ainda determinar a elaboração de um laudo sociológico para apurar se a exigência de realização de trabalho voluntário por todos os membros da comunidade indígena minka constituía questão de essencial importância para a cultura objeto de análise, decidiu ser plausível a imposição da obrigação a um casal que havia deixado de realizar os trabalhos de continuar realizando-os, sob pena de expulsão da comunidade. Do mesmo modo destaca-se a sentença 0006/2013, na qual o TCP acolheu a decisão da "Central Agrária do Cantão Província de Zongo Murillo do Departamento de La Paz", representante de 30 comunidades indígenas, que determinou a expulsão de um minerador do território, em respeito aos princípios, valores, normas e procedimentos próprios das comunidades indígenas, no marco de sua jurisdição.

Ocorre, entretanto, que apesar da relativização dos direitos humanos em tais casos, ainda pairam dúvidas acerca de até que ponto essa relativização é aceitável, sem que se coloque em risco a ideia de uniformização da proteção conferida pelos direitos humanos. A posição predominante, nessas hipóteses, consiste na afirmação de que as diferenças culturais devem ser aceitas, sem a imposição do Direito Estatal, desde que a conduta não cause dano irreparável ao indivíduo, que a tradição se fundamente em práticas baseadas em crenças enraizadas pela sociedade e que referidas tradições sejam fruto de uma escolha genuína e autônoma dos indivíduos pertencentes à comunidade (IOVANE, 2007), ou seja, que não sejam práticas impostas ao indivíduo, sem que este tenha a liberdade de escolha.

Caso não se encontre presente quaisquer desses requisitos, legitima-se a atuação estatal no sentido de procurar, por meio do diálogo com a comunidade, garantir a cooperação dos povos indígenas para a aceitação de alguns valores considerados essenciais pela comunidade internacional. É o que ocorreu quando do julgamento de um caso submetido à CC Colombiana contra a comunidade U'wa, ${ }^{8}$ a qual tinha como prática abandonar crianças caso esses nascessem gêmeos ou tivessem alguma deficiência. Neste a CC, apesar de considerar a cultura da comunidade, considerou intransponível o direito à vida, reconhecendo a impossibilidade da prática pela comunidade. Na hipótese, por meio do contato com a cultura ocidental e de um longo processo de reflexão, a comunidade abandonou a prática, por ela mesma, após a intervenção estatal, em razão de considerar que seu não exercício não afetaria a vida comunitária e as tradições locais.

Da mesma maneira, é o que ocorreu em alguns casos submetidos ao TCP, como os casos 1422/2012 e $1624 / 2012$, nos quais o Tribunal, após evidenciar que a expulsão de membros das comunidades pela autoridade indígena não constituía prática atrelada aos costumes e tradições próprias das comunidades em questão, determinou a reintegração dos membros à comunidade, ante a ofensa a direitos fundamentais destes.

Os julgados da CC, do TCP e da Corte IDH evidenciam a tentativa dos Tribunais em procurar estabelecer uma relação de aproximação com as comunidades tradicionais, servindo de parâmetro para que as demais Cortes também procurem, na análise de casos concretos, garantir a identidade, a autonomia e a diversidade cultural com as comunidades indígenas, em um processo de diálogo intercultural e respeito às diferenças. Ademais, também demonstram a possibilidade de coexistência do Direito Estatal e Internacional com o Direito local das comunidades indígenas, sem que essa coexistência afronte a proteção conferida pela comunidade

Corte Constitucional de Colombia (C.C.) (Colombian Constitutional Court), SentenciaT-030/00, 25 Jan. 2000. 
internacional aos direitos humanos, uma vez que a relativização de direitos apenas é legitimada, como visto, em casos específicos e após intensas reflexões, para a preservação da diversidade e da integridade cultural indígenas.

A questão é de essencial importância para que não haja a aniquilação das culturas tradicionais e para a construção de um universalismo de confluência, objetivos esses apenas alcançáveis a partir da progressiva atuação das Cortes Constitucionais dos Estados Nacionais quando deparadas com casos concretos de tensão entre direitos humanos e o direito costumeiro local.

Devem ser adotadas, nesse sentido, políticas que protejam, estimulem e enriqueçam a identidade e o patrimônio cultural, bem como garantam o absoluto respeito e apreço pelas diferentes culturas (CAMPELLO; SANTIAGO; ANDRADE, 2018). Nesse contexto, com base no exemplo da CC Colombiana e do TCP Boliviano, a conduta da Corte Brasileira assim como das demais Cortes Constitucionais dos países da região deve ser no sentido de progressivamente estabelecer um diálogo entre o Direito Estatal e o local, para assim garantir a coexistência entre as diferentes ordens.

Exige-se uma conversação, um diálogo, uma aceitação da cultura tradicional, com o sopesamento das circunstâncias do caso concreto, nos mesmos moldes do realizado pela Corte IDH, pela CC da Colômbia e pelo TCP da Bolívia, para averiguar, no caso concreto, a possibilidade de relativização das normas de direitos humanos ou, aos poucos, sem a imposição rigorosa da ordem estatal sobre a local, demonstrar à comunidade a possibilidade de progressivamente deixar de realizar a prática, por afrontar os direitos humanos e não constituir prática que, se eliminada, acabará com a cultura e tradição da comunidade, condição essa necessária para a coexistência de culturas e para a progressiva construção de direitos humanos universais, os quais são conscientes das diferenças culturais.

\section{CONCLUSÃO}

A ideia da aplicabilidade geral dos direitos humanos a todos os países e a todos os povos a despeito de suas diferentes circunstâncias históricas, culturais e religiosas, tem sido objeto de uma amplitude de reações nas últimas décadas, sendo contestada por grupos e culturas à margem do processo de construção e positivação desses direitos no espaço internacional. As críticas fundamentam-se na constatação de que para que se possa afirmar a universalidade proclamada pela Declaração de Direitos Humanos de 1948 é necessário que estes direitos possuam o condão de serem localmente relevantes, o que seria possível apenas a partir da acomodação da pluralidade inerente aos contextos locais.

Nesse tocante, o reconhecimento de uma diversidade global de culturas marca definitivamente o Direito Internacional Contemporâneo, representando não apenas um desafio para a estrutura, interpretação e aplicação dos direitos humanos, mas também um objetivo a ser perseguido para que o respeito às divergências seja assegurado e para que se logre êxito na formação de um legítimo universalismo dos direitos humanos, que necessariamente leva em consideração as peculiaridades locais. Assim, atualmente, após um longo processo de luta pelo reconhecimento da diversidade como fator inerente à tutela dos direitos humanos, busca-se uma contextualização desses direitos, reconhecendo-se que a universalidade ditada pela comunidade internacional apenas possui o condão de ser alcançada por meio do estabelecimento de um sincero e aberto diálogo intercultural.

Destaca-se que o reconhecimento da autonomia e identidade cultural dos povos indígenas insere-se nesse contexto de luta pelo respeito à diversidade cultural e pela negação de um universalismo baseado em falsas premissas, constituindo assunto de especial relevância, sobretudo na América Latina, ante a elevada quantidade de povos indígenas na região. Com relação a tais povos, o processo de articulação e diálogo torna-se estritamente necessário para que haja o devido respeito às tradições e ao direito costumeiro dos povos indígenas e para que não haja a imposição da cultura dominante da sociedade a tais povos.

Na prática, contudo, o que se observa é que em razão da evidente tensão existente entre algumas tradições indígenas e os direitos humanos, o estabelecimento de uma relação dialógica não é tarefa fácil. É em decorrência de tais tensões que se vislumbra o grande papel das Cortes Nacionais e Internacionais em procurar estabelecer constante contato e interação com as comunidades indígenas, como forma de harmonizar os interesses de preservação da integridade cultural do grupo e de proteção do indivíduo pertencente à comunidade, em consonância com os direitos humanos tutelados na ordem internacional. 
As Cortes têm o papel central de analisar, no caso concreto, se as limitações a alguns direitos humanos são justificáveis, como forma de garantia da preservação da identidade cultural ou, em sentido contrário, se não o são, caso em que se legitima a atuação estatal em prol da defesa do indivíduo. Essa constatação, entretanto, somente é possível a partir da adoção de uma postura dialógica, tal como efetuado pela Corte IDH, pela CC Colombiana e pelo TCP da Bolívia, as quais em diversos casos submetidos a sua apreciação procuraram identificar a legitimidade das práticas indígenas e, constatada essa, procuraram satisfazer o direito coletivo à diversidade cultural, mesmo com a limitação de alguns direitos fundamentais do indivíduo pertencente à comunidade.

No tocante às demais Cortes Constitucionais dos países da região, verifica-se que são poucos os julgados no mesmo sentido, tais Cortes limitando-se à discussão do direito dos povos indígenas à propriedade coletiva. A abertura constitucional desses países ao pluralismo, contudo, é evidente, fato que abre caminhos para o progressivo estabelecimento de uma relação dialógica entre o Direito Estatal e o local, no mesmo sentido em que efetuado pela Corte Colombiana, para assim garantir a coexistência entre as diferentes ordens.

Necessita-se, entretanto, de disposição política para seu estabelecimento, cada sociedade devendo abandonar preconceitos e crenças fixas para demonstrar a disposição, por meio do diálogo, à busca de uma convergente construção dos direitos humanos, de forma a assegurar a legitimidade do universalismo afirmado. Deve-se reconhecer que os direitos humanos ainda hoje não se encontram completamente construídos, havendo ainda um longo processo de luta para a afirmação da universalidade e transculturalidade desses direitos, luta essa que se inicia com o reconhecimento da pluralidade e diversidade.

\section{REFERÊNCIAS}

ACOSTA ALVARADO, Paola Andrea. Del diálogo interjudicial a la constitucionalización del derecho internacional: la red judicial latinoamericana como prueba y motor del constitucionalismo multinivel. 2015. Tese (Doutorado em Direito Internacional e Relações Internacionais) - Universidade Complutense de Madrid, Instituto Universitário de Investigação Ortega e Gasset, Madrid, 2015.

CAMPELLO, Lívia Gaigher; SANTIAGO, Mariana Ribeiro; ANDRADE, Sinara Lacerda. A valorização da identidade cultural como desafio à concretização do direito ao desenvolvimento. Revista de Direito Brasileira, São Paulo, SP, v. 19, n. 18, p. 3-19, jan./abr. 2018.

CANÇADO TRINDADE, Augusto. Desafios e conquistas do Direito Internacional dos Direitos Humanos no início do século XXI. In: MEDEIROS, Antônio Paulo Cachapuz de (org.). Desafios do Direito Internacional Contemporâneo. Brasília: Ministério das Relações exteriores, 2007. p. 207-321.

CANDAU, Vera M. Interculturalidade e educação escolar. In: CANDAU, Vera M. (org.). Reinventar a escola. Petrópolis: Vozes, 2000. p. 47-60.

CASSIN, René. La déclaration universelle et la mise en oeuvre des droits de l'homme. In: Recueil de Cours d l'Academie de Droit International, Tome 79, 1951 (II).

COMPARATO, Fábio Konder. A afirmação histórica dos direitos humanos. 7. ed. São Paulo: Saraiva, 2010.

DIMOULIS, Dimitri. Teoria geral dos direitos fundamentais. 5. ed. São Paulo: Atlas, 2014.

FLEURI, Reinaldo Matias. Intercultura e Educação. Revista Brasileira de Educação, Santa Catarina, n. 23, p. 16-35, maio/ago. 2003.

GALINDO, Bruno Cásar Machado Torres. Constituição e integração interestatal: defesa de uma teoria intercultural da constituição. 2004. Tese (Doutorado em Direito Público) - Universidade Federal de Pernambuco, Recife, 2004.

GIL, Antônio Carlos. Como elaborar projetos de pesquisa. 4. ed. São Paulo: Atlas, 2002.

GILBERT, Jeremie. Indigenous rights in the making: the United Nations Declaration on the rights of indigenous peoples. International Journal on Minority and Group Rights, v. 14, p. 207-230, 2007.

GODINHO, Fabiana de Oliveira. Diversidade cultural no Direito Internacional em um horizonte de justiça internacional. In: BOGDANDY, Armin von; PIOVESAN, Flávia; MORALES ANTONIAZZI, Mariela (coord.). Direitos humanos, democracia e integração jurídica na América do Sul. Rio de Janeiro: Editora Lumen Juris, 2010. p. 281-298.

GODINHO, Fabiana de Oliveira. The United Nations Declaration on the rights of indigenous peoples and the protection of indigenous rights in Brazil. In: BOGDANDY, Armin von; WOLFRUM, R. (ed.). Max Plank Yearbook of United Nations Law, v. 12, p. 247-286, 2008. 
GOMEZ ISA, Felipe. Cultural diversity, legal pluralism and human rights from an indigenous perspective: the approach by the Colombian Constitutional Court and the Inter-American Court of Human Rights. Human Rights Quarterly, v. 36, p. 722-755, 2014.

HABERMAS, Jürgen. Teoria da ação comunicativa, 2: sobre a crítica da razão funcionalista. Tradução Flávio Beno Siebeneichler. São Paulo: Editora WMF Martins Fontes, 2012.

HABERMAS, Jürgen. Sobre a legitimação pelos direitos humanos. In: MERLE, Jean-Christophe; MOREIRA, Luiz (org.). Direito e Legitimidade. São Paulo: Landy Editora, 2003. p. 67-82.

IOVANE, Massimo. The universality of Human Rights and the international protection of cultural diversity: some theoretical and practical considerations. International Journal on Minority and Group Rights, v. 14, p. 231-262, 2007.

KANT, Immanuel. Fundamentação da metafísica dos costumes. Tradução Paulo Quintela. Lisboa: Edições 70, 2007.

KROHLING, Aloísio. Os direitos humanos na perspectiva da antropologia cultural. Revista de Direitos e Garantias Fundamentais, Vitória, ES, n. 3, p. 155-182, jul./dez. 2008.

KUGELMANN, Dieter. The protection of minorities and indigenous peoples respecting cultural diversity. In: BOGDANDY, Armin von; WOLFRUM, R. (ed.). Max Plank Yearbook of United Nations Law. Leiden: Brill, 2007. p. 233-263. V. 11.

MAZZUOLI, Valerio de Oliveira. Curso de direito internacional público. 9. ed. São Paulo: Editora Revista dos Tribunais, 2015.

NASCIMENTO, Amos. From plural worldviews to global human rights discourses: on multiculturalism, interculturalism, and the possibility of an overlapping consensus. Revista Direito UFMS, v. 1, n. 1, p. 7-26, jul./dez. 2015.

NEVES, Marcelo. Transconstitucionalismo. São Paulo: Editora WMF Martins Fontes, 2009.

PEIXOTO, Érica de Souza Pessanha. Universalismo e relativismo cultural. Revista da Faculdade de Direito de Campos, Campos, n. 10, p. 255-281, jun. 2007.

PINEZ, Ana Keila Mosca. Infanticídio indígena, relativismo cultural e direitos humanos: elementos para reflexão. Aurora: Revista de Arte, Mídia e Política, v. 8, 2010.

PIOVESAN, Flávia. Direitos humanos e o direito constitucional internacional. 14. ed. São Paulo: Saraiva, 2013.

PIOVESAN, Flávia. Direitos Humanos: desafios e perspectivas contemporâneas. Revista TST, Brasília, v. 75, n. 1, p. 107-113, jan./mar 2009.

QUEIROZ, Cristina. Direito internacional e relações internacionais. Coimbra: Editora Coimbra, 2009.

RAMOS, André de Carvalho. Curso de Direitos Humanos. São Paulo: Saraiva, 2014.

RAWLS, John. The idea of an overlapping consensus. Oxford Journal of Legal Studies, v. 7, n. 1, p. 1-25, 1987.

RECH, Vilma Tereza. Pluralismo religioso: diálogo e alteridade no ensino religioso. 2009. Dissertação (Mestrado em Teologia) PUC-RS, Porto Alegre, 2009.

SANTOS, Natália de França. O infanticídio indígena no Brasil: o universalismo dos direitos humanos em face do relativismo cultural. Derecho y Cambio Social, v. 8, n. 25, 2011.

SANTOS, Boaventura de Sousa. Por uma concepção multicultural de direitos humanos. In: SANTOS, Boaventura de Sousa (org.). Reconhecer para libertar: os caminhos do cosmopolitismo multicultural. Rio de Janeiro: Civilização Brasileira, 2003, p. 427-462.

SEGATO, Rita Laura. Antropologia e Direitos Humanos: alteridade e ética no movimento de expansão dos direitos universais. Revista Mana, v. 12, n. 1, p. 207-236, 2006.

SEN, Amartya. Desenvolvimento como liberdade. Tradução Laura Teixeira Motta. São Paulo: Companhia das Letras, 2000.

SIDEKUM, Antônio. Multiculturalismo: desafios para a educação na América Latina. In: LAMPERT, Ernâni (org.). Educação na América Latina: encontros e desencontros. Pelotas: Educat, 2002. p. 77-96. V. 1.

SPAREMBERGER, Raquel Fabiana Lopes; RANGEL, Aline Luciane Lopes. Direitos Humanos: um olhar para a identidade, alteridade e novas concepções de cultura. In: LONDERO, Josirene Candido; BIRNFELD, Carlos André Hüning (org.). Direitos sociais fundamentais: contributo interdisciplinar para a redefinição das garantias de efetividade. Rio Grande do Sul: Editora da Furg, 2013. p. 245-275.

TAYLOR, Charles. Multiculturalismo: examinando a política de reconhecimento. Lisboa: Instituto Piaget, 1998. 